\title{
Genetic polymorphism among some wheat genotypes as revealed by RAPD and SCOT analysis
}

\author{
Sara B. H. Awaly \\ Genetics Department and Genetic Engineering Research Center, Faculty of Agriculture, Cairo University, Giza, Egypt.
}

Corresponding Author: Sara B. H. Awaly Genetics Department and Genetic Engineering Research Center, Faculty of Agriculture, Cairo University, Giza, Egypt.

Email: saraawaly@yahoo.com

Received date: 11 March 2018, Accepted date: 15 June 2018, Online date: 20 June 2018

Copyright: () 2018 Sara B. H. Awaly

. This is an open-access article distributed under the terms of the Creative Commons Attribution License, which permits unrestricted use, distribution, and reproduction in any medium, provided the original author and source are credited.

\begin{abstract}
Wheat (Triticum aestivum L.) is the fundamental crop, which gives staple food to great number of human population in the worldwide. Molecular characterization is extremely used by wheat breeders as another method for selecting genotypes with more potential and decrease the cost and time required to improve wheat crops productivity. In this study the genetic polymorphism among seven wheat cultivars using SCoT (Start Codon Targeted polymorphism) and RAPD (Random Amplified Polymorphic DNA) was determined. The SCoT analysis showed the higher polymorphism, where obtained 25 bands from 49 total bands representing 51\% polymorphic, on the other hand, RAPD analysis showed the 25 bands from 58 bands representing $43.1 \%$ polymorphic. Where, the SCoT-77 primer showed 12 bands as the highest number of bands, while SCoT-34 showed 5 bands as the lowest number of bands. On the other hand, The OPE-F-04 of RAPD scored 9 bands as a higher number of bands. Whereas, the OPE-A-07 scored 3 bands as the lowest number of bands. Therefore, the wheat cultivar specific SCoT and RAPD markers were detected, where, the Benisouf- 6 recorded 8 specific RAPD markers as the highest number, followed by three markers for Giza 171 then two markers for Giza 11. Among the SCoT specific cultivar markers recorded two markers are specific to Miser 1 followed by one marker for Benisouf-6. The dendrogram was generated according to the result of RAPD and SCoT markers to explain the genetic distances between seven wheat cultivars. The cluster analysis indicates the phylogenetic relationship among the different wheat cultivars used.
\end{abstract}

Key words: Wheat (Triticum aestivum L.), genetic diversity, RAPD, SCoT markers, Molecular markers.

\section{INTRODUCTION}

The fast growth of the world inhabitance and living levels and climatic changes increase request for food products Worldwide. Wheat constitutes an essential nutrient source for about $35 \%$ of the human population worldwide (Huseynova et. al., 2018).

Wheat is one member of the family Poaceae, which have major cereal crops. Wheat is a staple source of nutrient to great number of human population in the worldwide. It is a self-pollinated, allohexaploid crop (AABBDD) which having $2 n=6 x=42$ chromosome, grown in more than 70 countries of the world and keep one of the major sites in the food series (Dong et al., 2017 and Kumar et al., 2017).

Recent years in Egypt, there is a critical need to multiplication the productivity of wheat to decrease the food gap resulting from population increase Therefore, knowledge of the genetic variation of several wheat cultivars is useful to plant breeders to know the evolutionary relationships among genotypes to develop strategies to merge beneficial diversity in their breeding programs (El-Kadi et al., 2017 and Abdel-Lateif, and Hewedy, 2018). Consequently, the estimation of genetic diversity in the crops is fundamental assignments of breeding programs. It is assist in the selection of the species with extreme variety and better growth under extreme conditions (Etminan et al., 2016).

Molecular markers supply useful knowledge in plant breeding, mainly in researches on genetic variety and relationships among several plant species. Most of the molecular markers such as SCoT, RAPD, SSR and ISSR were used for the estimation of genetic variation in various significant agronomic crops. Among various molecular marker RAPD (Random Amplified Polymorphic DNA) have been frequently used to distinguish among closely related genotypes of wheat species due to efficiency, rapidity and simplicity for the screening of breeding population at large scale (Hlozáková et al., 2016, Soriano et al., 2016 and Kumar et al., 2017).

In recent years, many modern marker techniques were sophisticated such as SCoT polymorphism (Start codon targeted) are dominant and reproducible marker like RAPD markers. It is based on the short conserved region flanking the ATG start codon in genes. It was successfully applied to estimate genetic diversity, identify cultivars, quantitative trait loci (QTL) mapping and DNA fingerprinting in several cultivars, such as wheat (Vivodík et al., 2016 and khan et al., 2017).

In the current study RAPD and SCoT analyses were performed to uncover the genetic diversity and the phylogenetic relationships among seven Egyptian wheat cultivars. The genotype-specific molecular markers have been recorded. These markers will be useful markers for wheat breeding programs.

\section{MATERIALS AND METHODS}

Plant material: Seven elite Egyptian wheat cultivars namely Benisouf-6, Gemmiza-9, Giza-11, Giza-168, Giza-171, Miser-1, and Seds-12 have been utilized in this investigation. Seeds have been collected from the Wheat Department, Field Crops Research Institute, ARC, Giza, Egypt. Seeds have been germinated and grown in the greenhouse in order to obtained young leaves. 


\section{Molecular analysis \\ DNA isolation}

Genomic DNA has been isolated from young plant Leaves utilizing the CTAB method according to Rogers and Bendich (1985). Young plant Leaves (0.2 g) have been ground with liquid nitrogen and extracted using $1.0 \mathrm{ml}$ of preheated $2 \%$ CTAB buffer (cetyltrimethyl ammonium bromide ), containing $100 \mathrm{mM}$ Tris-HCI ( $\mathrm{pH}$ 8.0), $1.4 \mathrm{M}$ sodium chloride, $20 \mathrm{mM}$ EDTA, $0.1 \%$ of 2-mercaptoethanol. The mixture has been incubated at $65^{\circ} \mathrm{C}$ for one hour and then an equal volume of chloroform has been added and centrifuged at $10000 \mathrm{rpm}$ for 10 minutes. The aqueous phase has been transferred into new tubes and 3 volumes of cold absolute ethanol have been added to precipitate the DNA. After overnight incubation at $-20^{\circ} \mathrm{C}$, the mixture has been centrifuged at $10000 \mathrm{rpm}$ for $10 \mathrm{minutes}$. The pellet has been washed with $70 \%$ ethanol and dissolved in $20 \mu 1 \mathrm{H} 2 \mathrm{O}$. The quality of genomic DNA has been checked and separated in a $0.8 \%$ agarose gel and visualized after staining with ethidium bromide.

\section{RAPD-PCR amplification}

RAPD Analysis has been performed using 10 primers that have been selected from Operon Technology, USA (Table1). The reaction has been carried out in a volume of $20 \mu \mathrm{l}$ containing $2 \mu \mathrm{l}(50 \mathrm{ng}$ ) of genomic DNA template, $1 \mu \mathrm{l} 10 \mathrm{pmol}$ primers, $10 \mu \mathrm{l}$ Master Mix (GeneDireX) and $7 \mu \mathrm{l}$ distilled water. Amplification has been carried out in a programmed thermo-cycler (Biometra, Germany) using the following program, an initial DNA denaturation for 5 min at $94^{\circ} \mathrm{C}$ followed by 35 cycles each consisting of $1 \mathrm{~min}$ at $94{ }^{\circ} \mathrm{C}, 1 \mathrm{~min}$ at $34{ }^{\circ} \mathrm{C}$, and $1 \mathrm{~min}$ at $72{ }^{\circ} \mathrm{C}$ and finally at $72{ }^{\circ} \mathrm{C}$ for $5 \mathrm{~min}$. The product of PCR has been separated in a $1.2 \%$ agarose gel.

Table 1. The sequence of primers used in RAPD-PCR used to estimate the genetic diversity among the seven wheat cultivars

\begin{tabular}{ll}
\hline Primer names & Sequence \\
\hline OPE-A-07 & 5'-GAAACGGGTG-3' \\
OPE-A-18 & 5'-AGGTGACCGT-3' \\
OPE-B-04 & 5'-GGACTGGAGT-3' \\
OPE-C-11 & 5'-AAAGCTGCGG-3' \\
OPE-D-08 & 5'-GTGTGCCCCA-3' \\
OPE-F-04 & 5'-GGTGATCAGG-3' \\
OPE-G-12 & 5'-CAGCTCACGA-3' \\
OPE-G-14 & 5'-GGATGAGACC-3' \\
OPE-K-02 & 5'-GTCTCCGCAA-3' \\
OPE-K-14 & 5'-CCCGCTACAC-3' \\
\hline
\end{tabular}

\section{SCoT -PCR Analysis}

Six SCoT primers have been used, the primer names and their sequences has been shown in Table 2 and the PCR reaction has been carried out in a volume of 20 $\mu \mathrm{l}$ containing $2 \mu \mathrm{L}(50 \mathrm{ng})$ of genomic DNA template, $1 \mu \mathrm{L} 10$ pmol primer, $10 \mu \mathrm{L}$ Master Mix (GeneDireX) and $7 \mu \mathrm{L}$ distilled water. Amplification has been carried out in a programmed thermo-cycler (Biometra, Germany) using the following program, an initial DNA denaturation for 5 min at $94^{\circ} \mathrm{C}$ followed by 35 cycles each consisting of $1 \mathrm{~min}$ at $94{ }^{\circ} \mathrm{C}, 1 \mathrm{~min}$ at $50-53{ }^{\circ} \mathrm{C}$, and $1 \mathrm{~min}$ at $72{ }^{\circ} \mathrm{C}$ and finally at $72{ }^{\circ} \mathrm{C}$ for $5 \mathrm{~min}$. The product of PCR has been separated in a $1.2 \%$ agarose gel.

Table 2. The sequence of primers used in SCoT-PCR used to estimate the genetic diversity among the seven wheat cultivars

\begin{tabular}{ll}
\hline Primer & Sequence 5'-3' \\
\hline SCOT-13 & 5'- ACGACATGGCGACCATCG -3' \\
SCOT-14 & 5'- ACGACATGGCGACCACGC -3' \\
SCOT-26 & 5'- ACCATGGCTACCACCGTC-3' \\
SCOT-31 & 5' CCATGGCTACCACCGCCT -3' \\
SCOT-34 & 5'- ACCATGGCTACCACCGCA-3' \\
SCOT-77 & 5'- CC $\underline{\text { ATGGCTACCACTACCC-3' }}$ \\
\hline
\end{tabular}

\section{Data Scoring and Analysis}

The RAPD, SCoT gel images profile of banding patterns have been recorded and molecular weight of each band has been determined by DNA ladder. Data has been scored as (1) presence of the band and as (0) absence of band from SCoT and RAPD of amplification profile in each cultivar. The MVSP (Multi Variate Statistical Package) version 3.22 computer program has been utilized to calculate the coefficient of similarity between wheat cultivars using Jaccard's coefficient of similarity (Jaccard, 1908) and which utilized to make a dendrogram (Yang and Quiros 1993) by UPGMA method (un-weighted pair group method of arithmetic average) to evaluate the dendrogram.

\section{RESULTS AND DISCUSSION}

Morphological and agronomical characters are have been used for a long time in germplasm assessment, but those phenotypic markers can be influenced by environmental conditions. Thus, the use of this trait for categorization may result in inconsistency. Therefore, Genetic resources evaluation supports in the determination of various genotypes which can be used via breeding to develop suitable diversity. These are very important and beneficial for plant breeders to improve germplasm by inserting new genetic variety for certain characteristics into the plant breeding (Salem et al., 2008, Pagnotta et al., 2009, Zarkti et al., 2010 and Etminan et al., 2016). In this study, RAPD and SCoT primers have been recorded to investigate the genetic variation among seven wheat cultivars.

\section{Genetic variation revealed by RAPD markers}

Ten primers have been used to estimate the genetic variation among seven wheat cultivars that revealed 58 markers out of the 25 markers representing $43.1 \%$ polymorphism. The total number of polymorphic band different between 0 (OPE-D08) to 5 (OPE-F04) with a mean of 2.5 and the fragment size varied between 200 and 3500 bp. The OPE-F-04 primer revealed 9 bands as the highest number, whereas the OPE-A-07 primer showed 9 bands as the lowest number, showed that in Fig. 1, Table 3. The higher number of bands was indicated that the higher number of alleles and therefore increase variety in genotypes, thus the primer generated a higher number of bands the best implementation to detect the polymorphisms in plant genotypes. Table 4 reveals the genotype-specific markers for seven wheat cultivars. The B6 were scored eight specific markers followed by three specific markers for G171 and then two specific markers for G11 while none for GM9, G168, M1 and Sd12. Similar results had been reported earlier by Ali Ammar et al. (2013), Kumar et al. (2015) those authors agree with the present data in which RAPD show maximum polymorphism between different wheat cultivars. Hlozáková et al. (2016) identified and characterized the phylogenetic relationships between 24 European wheat cultivars by using SDS - PAGE and RAPD techniques to beneficial in future for genomic mapping studies leading to improvement of crop productivity. Kumar et al. (2017) studied the genetic variety using RAPD markers among ten Indian wheat genotypes. Tidke and Ranawade (2017) evaluated the genotype polymorphism among 36 wheat genotypes using RAPD analysis. 

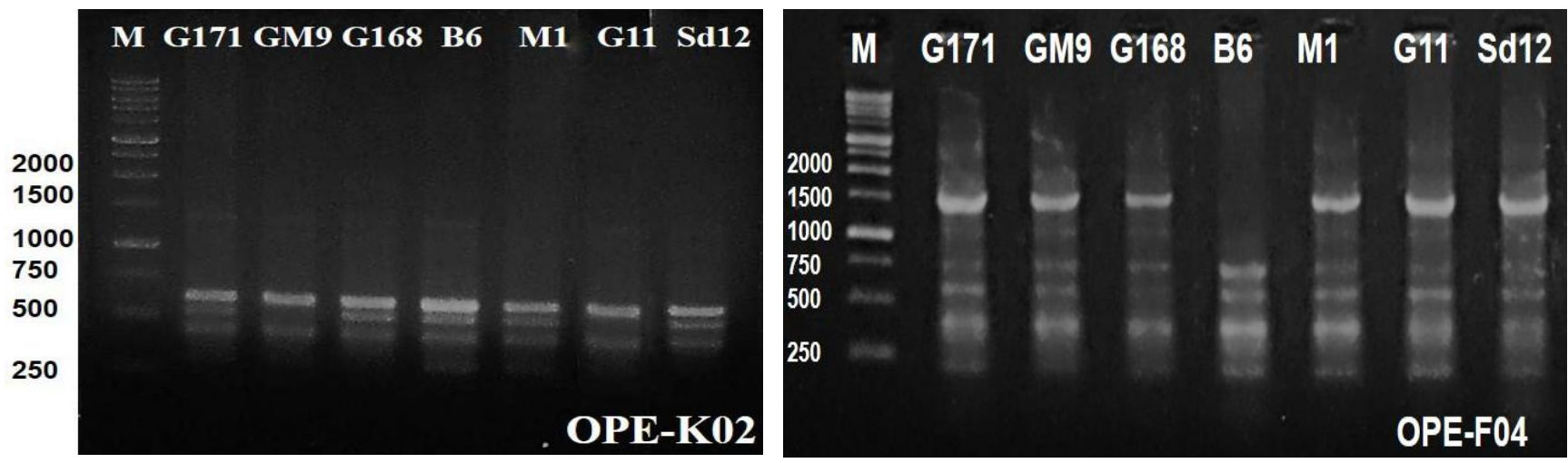

Fig. 1 Genetic polymorphism among seven wheat cultivars as revealed by RAPD analysis. M, 1 kbp DNA ladder.

Table 3 Total number of scorable bands, polymorphism percentage, and a band size of RAPD markers obtained by ten primers

\begin{tabular}{|c|c|c|c|c|}
\hline Primer & $\begin{array}{c}\text { Total scorable } \\
\text { band }\end{array}$ & Polymorphic band & Polymorphic \% & Band size range \\
\hline OPE-A07 & $\mathbf{3}$ & $\mathbf{1}$ & $\mathbf{3 3 . 3 3 \%}$ & $\mathbf{7 5 0 - 3 5 0}$ \\
OPE-A188 & 7 & $\mathbf{4}$ & $\mathbf{5 7 . 1 4 \%}$ & $\mathbf{2 0 0 0 - 3 0 0}$ \\
OPE- B04 & 4 & $\mathbf{2}$ & $\mathbf{5 0 \%}$ & $\mathbf{1 5 0 0 - 3 5 0}$ \\
OPE-C11 & 4 & $\mathbf{5 0 0 0}$ & $\mathbf{9 0 0 - 3 0 0}$ \\
OPE-D08 & 4 & $\mathbf{5}$ & $\mathbf{0 \%}$ & $\mathbf{2 5 0 0 - 2 0 0}$ \\
OPE-F04 & $\mathbf{9}$ & $\mathbf{5}$ & $\mathbf{5 5 . 5 5 \%}$ & $\mathbf{3 7 0 0 - 2 5 0}$ \\
OPE- G12 & $\mathbf{3}$ & $\mathbf{3}$ & $\mathbf{5 0 \%}$ & $\mathbf{1 5 0 0 - 2 5 0}$ \\
OPE-G14 & $\mathbf{6}$ & $\mathbf{3}$ & $\mathbf{4 2 . 8 5 \%}$ & $\mathbf{2 0 0 0 - 2 5 0}$ \\
OPE-K02 & 7 & $\mathbf{2}$ & $\mathbf{3 3 . 3 3 \%}$ & $\mathbf{1 3 0 0 - 3 0 0}$ \\
OPE-K14 & $\mathbf{6}$ & $\mathbf{2 5}$ & $\mathbf{4 3 . 1 \%}$ & \\
\hline Total & $\mathbf{5 8}$ & & & \\
\hline
\end{tabular}

Table 4 wheat cultivars and their specific RAPD markers

\begin{tabular}{|c|c|c|c|}
\hline \multirow{2}{*}{ Genotypes } & \multicolumn{2}{|c|}{ Total marker } \\
\cline { 2 - 3 } G171 & 1 & markers & \\
GM9 & - & OPE-A188(1500) & 3 \\
G168 & - & OPE-B4 (1500,350) & - \\
B6 & OPE-K14 (600) & - & - \\
& & OPE-F4(2000,1500,1000) & 8 \\
M1 & - & OPE-G12(1700), OPE-G14(250) & \\
G11 & OPE-K02(2000) and OPE-K14(450) & - \\
Sd12 & - & - & 2 \\
\hline Total & & OPE-A188(1000) & - \\
\hline
\end{tabular}

Genetic variation revealed by SCoT markers

Six SCoT markers were used for analysis the genetic variation among seven wheat cultivars and all of them resulted in polymorphic fingerprint patterns. The results showed that 25 bands from 49 total bands representing $51 \%$ polymorphism, showed in Fig. 2, Table 5 . The highest number of bands showed 12 bands by the SCoT-77 primer followed by 10 bands recorded by SCoT-13. But the lowest band number showed 5 bands by SCoT-34. Table 6 reveals the genotype-specific SCoT markers for the seven wheat cultivars. The M1 recorded the higher number of SCoT specific markers (2 markers), followed by one marker for B6 while none for G171, GM9, G168, G11 and Sd12. The percentage of polymorphism were accounted to define the level of polymorphism between cultivars and the total number of polymorphic band variety between $3-6$ polymorphic band with a mean of 2.5 ., shown in Table 5 . Whereas, the primers SCoT 13 and SCoT 77 revealed the higher number of bands (6 bands) representing 60\% and 50\%, respectively while the primer SCoT-14, SCoT-31 and SCoT-34 showed the lowest number of polymorphic bands (3) representing $42.9 \%, 42.9 \%$ and $60 \%$, respectively.

Similar, Cabo et al. (2014) evaluated the effectiveness of SCoT markers for analysis of hexaploid tritordeums and their parents. Etminan et al. (2016) determined the genetic variability of durum wheat cultivars using ISSR and SCoT markers. Vivodík et al., (2016) studied the genetic relationships between 40 maize cultivars from several areas of Europe using 20 Start codon targeted markers. Khan et al. (2017) evaluated the genetic variety among 13 genotypes of Mentha using 10 SCoT markers. Mohamed et al. (2017) used the short conserved locus flanking the ATG translation start codon (SCoT) markers analysis to detect the genetic diversity among T. aestivum cultivars. Abdel-Lateif and Hewedy (2018) used SCoT and ISSR analysis to investigate the genetic variation and relationships between eight Egyptian wheat cultivars. 

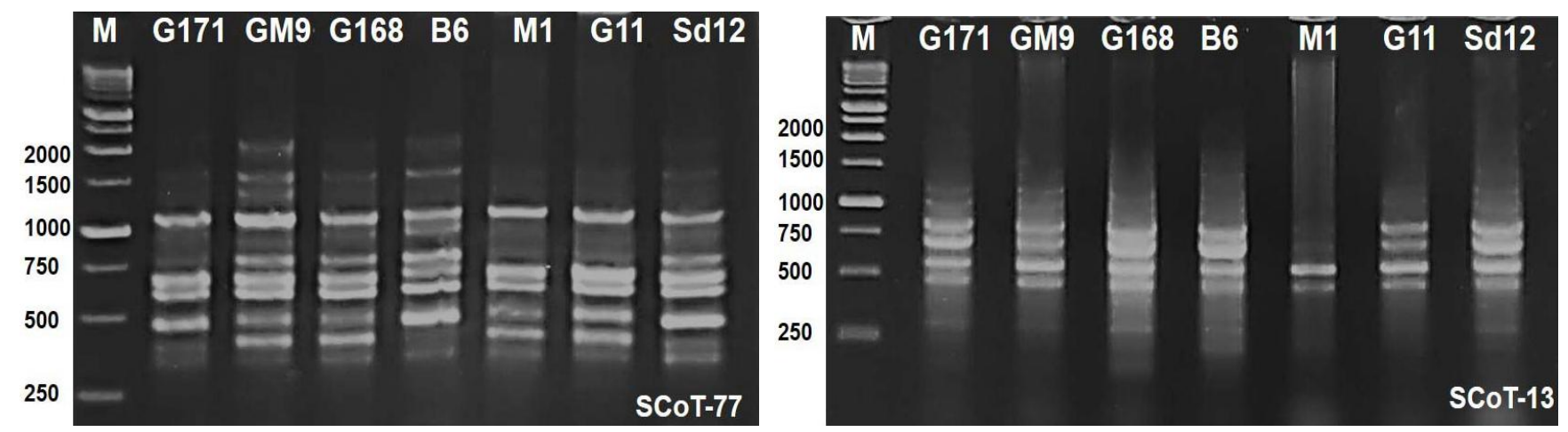

Fig. 2 Genetic polymorphism among seven wheat cultivars as revealed by SCoT analysis. M, 1 kbp DNA ladder.

Table 5 Total number of scorable bands, polymorphism percentage, and band size of SCoT markers obtained by six primers

\begin{tabular}{c|c|c|c|c}
\hline Primer & $\begin{array}{c}\text { Total scorable } \\
\text { band }\end{array}$ & Polymorphic band & Polymorphic \% & Band size range \\
\hline SCoT-13 & 10 & 6 & $60 \%$ & $1200-150$ \\
SCoT-14 & 7 & 3 & $42.9 \%$ & $1100-200$ \\
SCoT-26 & 8 & 4 & $50 \%$ & $1500-300$ \\
SCoT-31 & 7 & 3 & $42.9 \%$ & $900-200$ \\
SCoT-34 & 5 & 3 & $60 \%$ & $1500-400$ \\
SCoT-77 & 12 & 6 & $50 \%$ & $2000-200$ \\
\hline Total & 49 & 25 & $51 \%$ & \\
\hline
\end{tabular}

Table 6 wheat cultivars and their specific SCoT markers

\begin{tabular}{c|c|c}
\hline Genotypes & markers & Total marker \\
\hline G171 & - & - \\
GM9 & - & - \\
G168 & - & - \\
B6 & SCoT-77 (450) & 1 \\
M1 & SCoT-34 (1500-1000) & 2 \\
G11 & - & - \\
Sd12 & - & - \\
\hline Total & & 3 \\
\hline
\end{tabular}

The relationships among seven wheat cultivars

Jaccard's coefficient (Jaccard, 1908) similarity matrix have been calculated to estimate the genetic divergence and relationship among wheat genotypes. The wheat cultivars GM9 and G168 show the highest similarity percentage $92.7 \%$ and $77.3 \%$ as revealed by RAPD and SCoT analyses respectively. While the cultivars G171 and B6 showed the lowest similarity percentages $64.9 \%$ and $62.5 \%$ as revealed by RAPD and SCoT analyses (Table 7 and 8 ). Moreover, breeders usually share breeding material and use genetically similar parents in breeding programs have led to worry of lack of genetic diversity. Therefore, the genetic diversity in the population is helpful in developing improved wheat cultivars (Kumar et al., 2017 and El-Esawi et al., 2018).

Table 7. Similarity coefficient among the seven wheat cultivars calculated according to Jaccard's coefficient revealed by RAPD analysis

\begin{tabular}{l|lllllll}
\hline & G171 & GM9 & G168 & B6 & M1 & G11 & Sd12 \\
\hline G171 & $\mathbf{1}$ & & & & & & \\
GM9 & 0.857 & $\mathbf{1}$ & & & & & \\
G168 & 0.821 & $\mathbf{0 . 9 2 7}$ & $\mathbf{1}$ & & & & \\
B6 & $\mathbf{0 . 6 4 9}$ & 0.75 & 0.778 & $\mathbf{1}$ & & & \\
M1 & 0.889 & 0.893 & 0.926 & 0.714 & $\mathbf{1}$ & $\mathbf{1}$ & \\
G11 & 0.8 & 0.839 & 0.804 & 0.691 & 0.87 & 0.852 & $\mathbf{1}$ \\
Sd12 & 0.87 & 0.875 & 0.873 & 0.727 & 0.907 & 0 \\
\hline
\end{tabular}

Table 8. Similarity coefficient among the seven wheat cultivars calculated according to Jaccard's coefficient revealed by SCoT analysis

\begin{tabular}{l|lllllll}
\hline & G171 & GM9 & G168 & B6 & M1 & G11 & Sd12 \\
\hline G171 & $\mathbf{1}$ & & & & & & \\
GM9 & 0.884 & $\mathbf{1}$ & & & & & \\
G168 & 0.756 & $\mathbf{0 . 7 7 3}$ & $\mathbf{1}$ & & & & \\
B6 & $\mathbf{0 . 6 2 5}$ & 0.711 & 0.744 & $\mathbf{1}$ & & & \\
M1 & 0.636 & 0.614 & 0.643 & 0.659 & $\mathbf{1}$ & & $\mathbf{1}$ \\
G11 & 0.81 & 0.744 & 0.622 & 0.636 & 0.692 & $\mathbf{1}$ & $\mathbf{1}$ \\
Sd12 & 0.804 & 0.822 & 0.739 & 0.756 & 0.659 & 0.791 & \\
\hline
\end{tabular}

The dendrogram constructed on the basis of the similarity coefficient showed by pooled RAPD-SCoT analysis (Fig-3) that the seven wheat cultivars can be divided into two main clusters, the first cluster included two main subclusters, and the first one containing G171 and GM9. While the second subcluster containing B6 and G168. On the other hand, the second cluster consisted of two main subclusters, the first one including M1 only, while the second subcluster contained Sd12 and G11. 


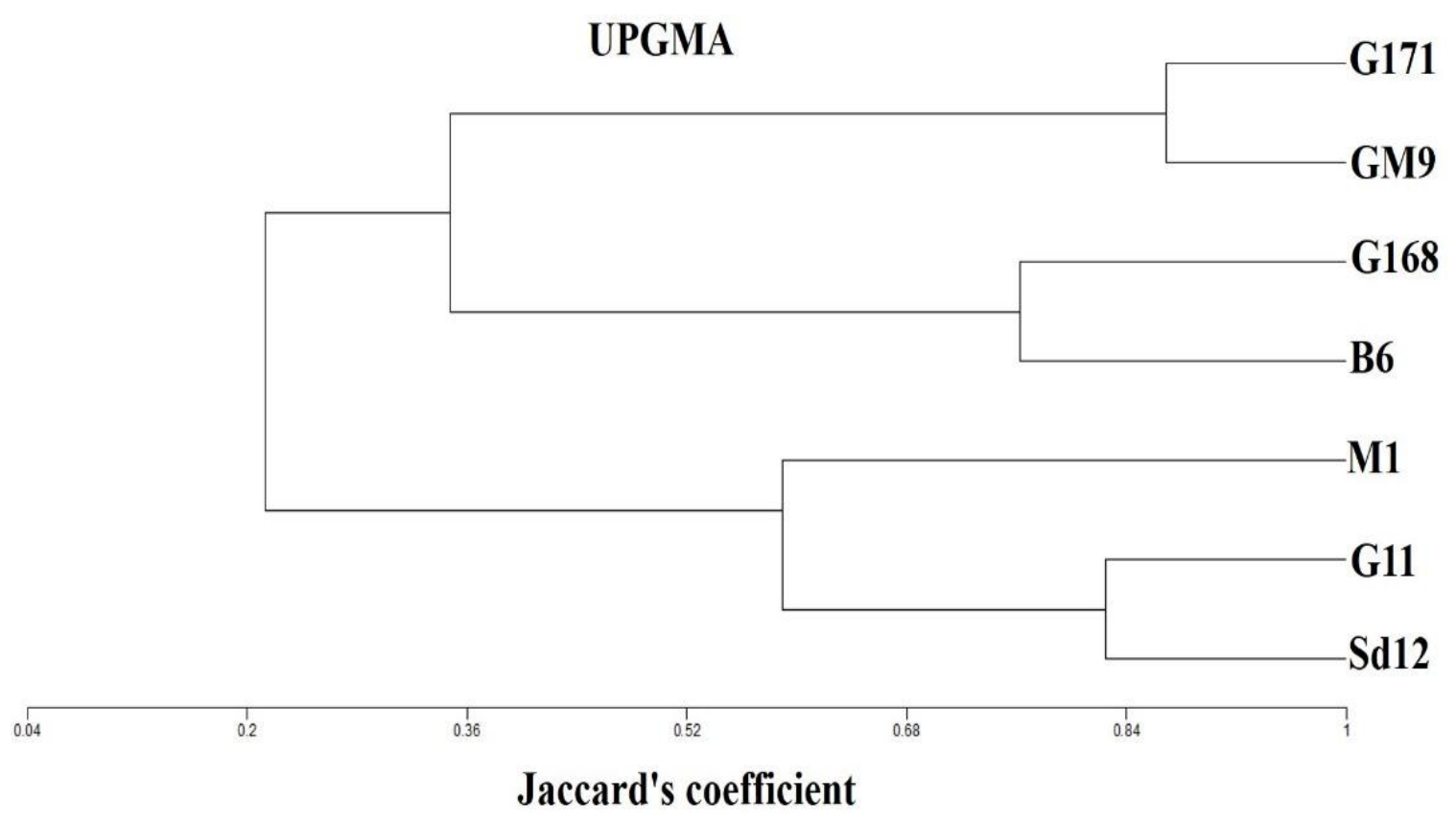

Fig. 3 Phylogenetic tree of seven wheat cultivars based on pooled RAPD-SCoT markers

\section{CONCLUSION}

The results of this study concluded that the high number of polymorphic bands and the high PIC (polymorphic information content) showed the strong of SCoT and RAPD markers in fingerprinting and diversity analyses. This led to successful the RAPD and SCoT analysis in assessing the genetic variation and the genetic relationships between the wheat cultivars and they can be applied as specific markers for identification and isolation of several cultivars for utilizing in wheat improvement programs. Furthermore, this study detects a higher genetic diversity between estimated cultivars that can be utilized to improvement and development of novel genotypes.

\section{Acknowledgements}

The author expresses deep sense of gratitude and many thanks to Prof. Dr. Reda E.A. Moghaieb for all the support, assistance, his kind advices and constant encouragements to carry out this work and critical reading of the manuscript and provide chemicals in Genetic Engineering Research Center, Faculty of Agriculture, Cairo University, Egypt.

\section{REFERENCES}

Abdel-Lateif, K. S. and O. A. Hewedy, 2018. Genetic diversity among Egyptian wheat cultivars using SCoT and ISSR markers. SABRAO J. of Breeding and Genetics, 50 (1) 36-45.

Ammar, A., A. Nawab, A. Imran, A. Muhammad, U. Nimat, A. Zahoor, 2013. Morphological and genetic diversity of Pakistani Wheat germplasm under drought stress. Inter. J. of Advancements in Research and Technology, 2(5):186-193. ISSN 2278-7763

Cabo, S., L. Ferreira, A. Carvalho, P. Martins-Lopes, A. António Martín, and J. E. Lima-Brito, 2014. Potential of Start Codon Targeted (SCoT) markers for DNA fingerprinting of newly synthesized tritordeums and their respective parents, J Appl. Genetics, 55:307-312. DOI: 10.1007/s13353-014-0211-3.

Dong, Z., Y. Yang, K. Zhang, Y. Li, J. Wang, Z. Wang, X. Liu, H. Qin, and D. Wang, 2017. Development of a new set of molecular markers for examining GluA1 variants in common wheat and ancestral species. . PLoS ONE 12(7):1-16. Doi: 10.1371/0180766.

El-Esawi, M. A., J. Witczak, A. El-F. Abomohra, H. M. Ali, M. S. Elshikh, and M. Ahmad, 2018. Analysis of the Genetic Diversity and Population Structure of Austrian and Belgian Wheat Germplasm within a Regional Context Based on DArT Markers. Genes, 9 (47): 1-13. Doi: 10.3390/genes9010047.

El-Kadi, D. A., D. S. Darwish, R. E. A. Moghaieb, and I. H. Yacoub, 2017. Variation and Association among Yield components and Quality Traits of Some Egyptian Bread Wheat Genotypes. Research J. of Pharmaceutical, Biological and Chemical Science, 8(3):2521-2527. ISSN: 0975-8585

Etminan, A., A. Pour-Aboughadareh, R. Mohammadi, A. Ahmadi-Rad, A. Noori, Z. Mahdavian, and Z. Moradi, 2016. Applicability of start codon targeted (SCoT) and inter-simple sequence repeat (ISSR) markers for genetic diversity analysis in durum wheat genotypes. Biotech. and Biotech. Equipment, 30 (6) 1075-1081. DOI: 10.1080/13102818.2016.1228478.

Hlozáková, T. K., E. Gregová, M. Vivodík, and Z. Gálová, 2016. Genetic diversity of European cultivars of common wheat (Triticum aestivum L.) based on RAPD and protein markers. J. of Central European Agri., 17(4): 957-969. DOI: 10.5513/JCEA01/17.4.1798.

Jaccard, P. (1908): Nouvelles recherches sur la distribution florale. Bull. Soc. Vaudoise. Sci. Nat., 44:223-270.

Khan, N., S. Singh, and S. S. Dhawan, 2017. Development of species specific SCoT markers and analysis of genetic diversity among Mentha genotypes. IJISET, 4 (2): 244- 264. ISSN: $2348-7968$

Kumar, A., R. Singh, R. Singh, and S. R. Sengar, 2015. Molecular Approach for Detection of Plant pathogen. An Inter. J. of Biological Sciences Biotech today, 5(2):14 -19. DOI : 10.5958/2322-0996.2015.00017.4

Kumar, A., R. S. Sengar, V. P. Rao, G. Shukla, R. Dixit, and R. Singh, 2017. Assessment of genetic diversity in bread wheat (Triticum aestivum L.) using RAPD markers. J. of Applied and Natural Science, 9 (3): 1751 -1755. ISSN: 0974-9411 
Mohamed, A. S. H., M. Ibrahim, S. S. Teleb, and M. E. Tantawy, 2017. SEM and SCoT markers unveil new taxonomic and genetic insights about some northern african Triticum aestivum L. cultivars. Vegetos, 30:1-11. DOI: 10.4172/2229-4473.1000206.

Pagnotta, M. A., L. Mondini, P. Codianni, and C. Fares, 2009. Agronomical, quality, and molecular characterization of twenty Italian emmer wheat (Triticum dicoccon) accessions. Genetic Resources and Crop Evolution, 56: 299-310. DOI 10.1007/s10722-008-9364-4.

Rogers, S. O., and A. J. Bendich, 1985. Extraction of DNA from milligram amount of fresh herbarium, and mummified plant tissue. Plant Mol. Biol., 5:69-76.

Tidke, S. D., and P. S. Ranawade, 2017. Genetic Analysis and RAPD Polymorphism in Wheat (Triticum aestivum L.) Genotypes. Int. J. Curr. Microbiol. App. Sci., 6(3): 239-246. DOI: $10.20546 / 603.026$.

Salem, K. F. M., A. M. El-Zanaty, and R. M. Esmail, 2008. Assessing wheat (Triticum Aestivum L.) genetic diversity using morphological characters and microsatellite markers. World J. of Agri. Sciences., 4: 538-544. ISSN 1817-3047

Soriano, J. M., D. Villegas, M. J. Aranzana, L. F. G. Del Moral, and C. Royo, 2016. Genetic structure of modern durum wheat cultivars and Mediterranean landraces matches with their agronomic performance. PlosOne, 11(8), e0160983. DOI:10.1371/0160983.

Vivodík, M., Z. Gálová, Ž. Balážová, and L. Petrovičová, 2016. Start codon targeted (scot) polymorphism reveals genetic diversity in European old maize (Zea Mays L.) Genotypes. Potravinarstvo, 10 (1): 563-569. Doi:10.5219/660.

Zarkti, H., H. Ouabbou, A. Hilali, and S. M. Udupa, 2010. Detection of genetic diversity in Moroccan durum wheat accessions using agro-morphological traits and microsatellite markers. African journal of agricultural research, 5: 1837-1844. ISSN 1991-637 